\title{
Erratum to: The activity of the artemisinic aldehyde $\Delta 11(13)$ reductase promoter is important for artemisinin yield in different chemotypes of Artemisia annua L.
}

\author{
Ke Yang ${ }^{1}$ Sajad Rashidi Monfared ${ }^{1,2} \cdot$ Hongzhen Wang ${ }^{1,3} \cdot$ Anneli Lundgren ${ }^{1}$ • \\ Peter E. Brodelius ${ }^{1}$
}

Published online: 22 May 2015

(C) Springer Science+Business Media Dordrecht 2015

\section{Erratum to: Plant Mol Biol \\ DOI 10.1007/s11103-015-0284-3}

Due to an unfortunate misunderstanding, the first name and surname of the second author were interchanged in the original publication. The correct representation of the author and his affiliation is listed above and below and should be treated as definitive by the reader.

The online version of the original article can be found under doi:10.1007/s11103-015-0284-3.

Peter E. Brodelius

peter.brodelius@1nu.se

1 Department of Chemistry and Biomedical Sciences, Linnaeus University, Kalmar, Sweden

2 Present Address: Department of Plant Breeding and Biotechnology, Faculty of Agriculture, Tarbiat Modares University, 14115-336 Tehran, Iran

3 Present Address: Zhejiang Agriculture and Forestry University, Linan 311300, Zhejiang, People's Republic of China 